\title{
Sinais adjetivos da Libras em uma abordagem cognitiva*
}

\author{
Adjective signs of Libras in a cognitive approach
}

\author{
Glênia Aguiar Belarmino da Silva Sessa ${ }^{1}$ \\ Sandra Pereira Bernardo ${ }^{2}$
}

\begin{abstract}
Resumo: Analisam-se processos cognitivos subjacentes ao sentido de cinco sinais adjetivos da Língua Brasileira de Sinais que expressam emoção, em uma abordagem cognitiva. Para cumprir tal objetivo, partiu-se das teorias da metáfora e da metonímia conceptuais, dos conceitos de corporificação e iconicidade cognitiva. Estruturas conceptuais, como esquema imagético, frames e espaços mentais, também compõem o arcabouço teórico deste trabalho. Tais sinais foram coletados do Dicionário Digital da Língua Brasileira de Sinais do Instituto Nacional de Educação de Surdos, caracterizando, portanto, uma abordagem lexical. Trata-se de parte de uma pesquisa mais ampla com estudo de oitenta sinais. Após a investigação, postularam-se as projeções metonímicas EXPRESSÃO NÃO MANUAL POR EMOÇÃO, INTENSIDADE/DIREÇÃO DE MOVIMENTO POR EMOÇÃO, CONTENÇÃO POR EMOÇÃO e CONTATO POR EMOÇÃO para construção de sentido os adjetivos para emoção em Libras, considerando a relação entre os parâmetros de produção dos sinais e seus sentidos.
\end{abstract}

Palavras-chave: Sinais Adjetivos da Libras. Metonímia Conceptual. Metáfora Conceptual. Base Corpórea da Construção do Sentido. Esquemas Imagéticos, Frames e Espaços Mentais.

Abstract: Cognitive processes underlying the meaning of five adjective signs from Brazilian Sign Language that express emotion are analyzed in a cognitive approach. In order to accomplish this objective, we started from the theories of metaphor and conceptual metonymy, from the concepts of embodiment and cognitive iconicity. Conceptual structures, such as image schema, frames and mental spaces, are also part of the theoretical framework of this work. Such signs were collected from the Brazilian Sign Language Digital Dictionary of the National Institute of Education for the Deaf, thus characterizing a lexical approach. It is part of a broader research study of eighty signs. After the investigation, the metonymic projections NONMANUAL EXPRESSION BY EMOTION, INTENSITY/DIRECTION OF MOVEMENT BY EMOTION, CONTAINMENT BY EMOTION and CONTACT BY EMOTION were postulated for meaning construction, the adjectives for emotion in Libras, considering the relationship between the production parameters of signs and their senses.

Keywords: Adjective Signs of Libras. Conceptual Metonymy. Conceptual Metaphor. Embodied Basis of the Construction of Meaning. Image Schemas, Frames and Mental Spaces.

\footnotetext{
${ }^{*}$ Produção bibliográfica vinculada ao projeto FAPERJ n ${ }^{\circ}$ E-26/010.000145/2016.

${ }^{1}$ Universidade do Estado do Rio de Janeiro, Programa de Pós-Graduação em Letras, Rio de Janeiro, RJ, Brasil. Endereço eletrônico: gleniasessa@gmail.com.

${ }^{2}$ Universidade do Estado do Rio de Janeiro, Instituto de Letras, Departamento de Estudos da Linguagem, Programa de Pós-Graduação em Letras, Rio de Janeiro, RJ, Brasil. Endereço eletrônico: sandrabernardo61@ @mail.com.
} 


\section{Introdução}

Apresentamos uma análise dos processos cognitivos subjacentes ao sentido de cinco sinais adjetivos da Libras: ABORRECIDO, CONTENTE, FOGOSO, DOIDO e OTIMISTA. Para alcançar esse objetivo, baseamo-nos no arcabouço da Linguística Cognitiva, a saber: teorias da metáfora e da metonímia conceptuais (LAKOFF; JOHNSON, 2002[1980]; KÖVECSES, 2006, 2010, 2020 entre outros estudos), estruturas conceptuais, como esquemas imagéticos, frames, domínios e espaços mentais, corporificação da construção de sentidos e iconicidade cognitiva (WILCOX, 2004; NUNES, 2014), entre outros conceitos.

Adotamos um critério lexical para seleção e análise dos sinais adjetivos, porque buscamos os aspectos conceptuais basilares da construção de sentido dos sinais em estudo, conforme as definições adotadas pelo dicionário da Libras escolhido. Logo, embora, como em qualquer língua, ocorram variações de sinalização e sentido dos sinais da Libras, conforme o contexto de uso, a análise proposta aqui concentra-se nos sinais adjetivos descontextualizados discursivamente.

Os sinais selecionados foram coletados da versão 2.0 do Dicionário Digital da Língua Brasileira de Sinais do Instituto Nacional de Educação de Surdos (INES). Essa versão, divulgada em 2005, contava com mais de 5.000 sinais $^{3}$. Inicialmente, foram selecionados 120 sinais que expressavam propriedades humanas, como estados mentais ou comportamento, classificados como adjetivos pelo site. Contamos com um total 80 adjetivos, após a exclusão de sinais soletrados e repetidos. Os casos de repetição foram observados por meio da opção de acesso pela língua portuguesa; por exemplo, como os verbetes IGNORANTE e TEIMOSO apresentavam o mesmo sinal, selecionamos somente o primeiro.

Assim, neste artigo, retomamos alguns achados dessa pesquisa, realizada por Sessa $(2018)^{4}$, acrescidos de novas reflexões, com base em Kövecses (2020). Os adjetivos analisados aqui representam cinco dos sete grupos categoriais postulados por Sessa (2018), considerando os processos cognitivos subjacentes à construção de sentido dos sinais para emoção.

Nas próximas seções, trataremos, respectivamente, da fundamentação teórica e dos procedimentos metodológicos. Em seguida, passaremos à análise dos sinais selecionados. Por último, teceremos as considerações finais.

\footnotetext{
${ }^{3}$ Embora, durante a seleção de dados, em 2017, tenha ocorrido atualização no dicionário, mantivemos os oitenta sinais já selecionados, visto que não se tratava de um estudo quantitativo.

${ }^{4}$ Dissertação orientada por Sandra Pereira Bernardo.
} 


\section{Fundamentos linguístico-cognitivos da construção de sentido}

Uma das assunções basilares da Linguística Cognitiva (LC) é a visão experiencialista, em que a natureza orgânica influencia a experiência de mundo refletida no uso da língua. Essa concepção subjaz à hipótese da corporificação dos sentidos, segundo à qual a mente é corporificada, por isso as experiências do corpo assumem um papel fundamental no modo como pensamos e na formação da gramática. Assim, gramática e significado são duas faces de uma mesma moeda, ou seja, no escopo da semântica cognitiva, é imprescindível entender como o sistema linguístico se relaciona com a experiência corporificada (EVANS; GREEN, 2006).

Mark Johnson (1987) destaca que a corporificação (embodiment) é encontrada na cognição humana, porque o que falamos ou pensamos está relacionado à experiência corporal sobre como percebemos e concebemos o mundo ao nosso redor. Logo, sentidos, habilidades motoras e perceptuais estão ligados à linguagem e à forma como se conceptualizam conceitos na mente. Lakoff e Johnson (2002[1980]) descrevem que a mente seria "corporificada", estruturada através das experiências corporais, e não uma entidade puramente metafísica e independente do corpo.

Da mesma forma, a razão é também "corporificada", pois se origina tanto da natureza do cérebro, como das peculiaridades dos corpos e das experiências no mundo em que vivemos. Segundo Ferrari (2011, p. 21), portanto, “a investigação da mente humana não pode ser separada do corpo, de modo que a experiência, a cognição e a realidade são concebidas a partir de uma ancoragem corporal. Um exemplo clássico de corporificação é encontrado na forma megbé - 'costas' - da língua Ewe, em que conceitos concretos relacionados ao corpo humano se abstratizam progressivamente para referir outros conceitos na língua, conforme o seguinte caminho de conceptualização: PESSOA [costas] $\rightarrow$ OBJETO [atrás do objeto] $\rightarrow$ ESPAÇO [atrás do monte] $\rightarrow$ TEMPO [atrasado] $\rightarrow$ PROPRIEDADE [retardado mental] (HEINE; CLAUDI; HÜNNEMEYER, 1991).

Como os seres humanos, não são apenas entidades biológicas, mas seres sociais imersos em uma cultura, as línguas podem revelar identidades, uma vez que incorporam a experiência histórica e cultural de grupos de falantes. A organização do conhecimento de mundo reflete-se na atribuição dos significados; logo, o significado linguístico é dinâmico e flexível, a depender das experiências vivenciadas pelos indivíduos (GEERAERTS, 2006). Portanto, não existe um conjunto rígido de traços que se aplicam a todos os elementos, ainda que esses estejam agrupados em uma mesma categoria, o que existe são apenas padrões mais prototípicos em relação a outros menos prototípicos. Ainda sobre o significado linguístico, no âmbito da LC, este é concebido como enciclopédico e não-autônomo, visto que, como não está separado das 
outras formas de conhecimento, não se relaciona unicamente às faculdades mentais do indivíduo, mas a toda a interação dele em sociedade.

Com base em Lakoff (1987), Langacker (1987) e Rosch (1978), podemos considerar que grande parte do nosso conhecimento sobre o mundo provém de grandes sistemas de conceitos organizados hierarquicamente e conectados conforme o nível de esquematicidade, definida por Langacker (1987, p. 492) como "uma precisão relativa da especificação ao longo de um ou mais parâmetros". Entre as estruturas conceptuais que organizam conceptualmente nossa forma de pensar e estar no mundo, encontram-se os esquemas imagéticos, os frames e os domínios.

Os esquemas imagéticos são estruturas pré-conceituais essenciais que impregnam experiência com significado (JOHNSON, 1987; LAKOFF, 1987). Formam-se por meio da percepção sensório-motora das experiências humanas mais primitivas, ligadas a uma série de situações que experienciamos em nossa interação com o ambiente (GIBBS; COLSTON, 2006[1995]) e manipulação de objetos. Consistem em gestalts altamente esquemáticas que capturam os contornos estruturais da experiência sensório-motora, integrando informações de múltiplas modalidades. Existem como padrões contínuos e analógicos, subjacentes à percepção consciente, antes e independentemente de outros conceitos. São estruturados internamente e altamente flexíveis, de modo que se manifestam nas inúmeras transformações que sofrem em vários contextos experienciais, todos intimamente relacionados aos princípios perceptivos (gestalt) (HAMPE, 2005).

Os frames foram definidos como qualquer "sistema de conceitos relacionados, de tal forma que para entender qualquer um deles é necessário compreender toda a estrutura em que se enquadram" (FILLMORE, 2006, p. 373). A noção de domínio foi definida por Langacker (1987, p. 488) como "uma área coerente de conceituação em relação à qual unidades semânticas podem ser caracterizadas”. Frames e domínios são menos esquemáticos, portanto mais específicos, que os esquemas imagéticos (KÖVECSES, 2020). Em sua Teoria da Metáfora Conceptual Estendida, Kövecses (2020) trabalha com a noção de domínio matriz, diferenciando, assim, essa estrutura conceptual do frame, que seria menos esquemático que o domínio-matriz. Contudo, na análise desenvolvida aqui, como não abarcaremos o nível dos domínios-matrizes, não diferenciaremos frames e domínios.

Outra estrutura conceptual ativada na construção de sentido são os espaços mentais, estruturas conceptuais menos esquemáticas que funcionam operadores do processamento discursivo, ou seja, o espaço da conceptualização, em que estariam operando informações contextuais e linguísticas. Os espaços mentais são mais específicos que frames e domínios, 
porque organizam e ativam material conceptual processado na memória de trabalho, enquanto os dois últimos organizam e estruturam conteúdos conceptuais armazenados na memória de longo prazo. Mesmo quando abordamos os sentidos adjetivais dos sinais da Libras descontextualizados, espaços mentais são ativados, ao pensarmos nos conceitos que expressam, visto que funcionam como base para ativação de frames/domínios e esquemas imagéticos, apesar do contexto menos especificado em uma abordagem lexical.

Espaços mentais, frames/domínios e esquemas imagéticos fundamentam a ativação de metáforas e metonímias conceptuais, dois processos cognitivos que permeiam o uso da linguagem. Segundo Lakoff e Johnson (2002, p. 47-48), a "essência da metáfora é compreender e experienciar uma coisa em termos da outra". Em frases como "Seus argumentos são indefensáveis" e "Ele atacou todos os pontos fracos da minha argumentação", o conceito de DISCUSSÃO, o domínio-alvo, é compreendido em termos do conceito de GUERRA, o domíniofonte. As expressões linguísticas indefensáveis e atacou todos os pontos fracos são consideradas expressões metafóricas, que evidenciam a metáfora conceptual subjacente DISCUSSÃO É GUERRA ${ }^{5}$. Expressões provenientes do vocabulário de guerra evidenciam uma maneira sistemática de conceituar o ato de discutir.

Semelhantes às metáforas, no âmbito da LC, metonímias também possuem uma natureza conceptual, revelada por expressões linguísticas metonímicas. Em termos gerais, tratase de p/rocesso em que uma entidade, um veículo, dirige a atenção, ou propicia acesso mental, à outra entidade, um alvo. Assim, na frase "Washington está negociando com Moscou", Washington e Moscou seriam entidades veículos, enquanto as capitais de Estados Unidos e Rússia seriam entidades alvos. Caracteristicamente, o veículo metonimicamente relacionado e a entidade alvo são afins, ou seja, "próximos" um do outro no espaço conceitual, da mesma forma que um produtor se relaciona conceitualmente a um produto.

No que tange à relação entre metáfora e metonímia, os linguistas cognitivos dividem-se quanto à admissão de um estágio metonímico na conceptualização metafórica. Para alguns, esse estágio metonímico seria concebível nos casos de metáforas que surgem da correlação de experiências corporificadas mais básicas.

A esse respeito, concordamos com Kövecses (2020), para quem metáforas baseadas em correlação de experiência emergem de representações mentais a partir de estruturas conceptuais, como os frames, por meio de um estágio metonímico. Ao serem codificadas linguisticamente, as correlações experienciais devem ser conceptualizadas e, uma vez

\footnotetext{
${ }^{5}$ Em Linguística Cognitiva, fontes em versalete são usadas para referenciar o nível conceptual de conceitos e processos cognitivos.
} 
verbalizadas, as correlações experienciais também se tornam (associações) conceptuais. Kövecses (2020) estabelece a relação entre metáfora e metonímia, baseando-se na visão de um sistema conceptual organizado hierarquicamente em diferentes níveis de esquematicidade das estruturas conceptuais.

Outro conceito caro ao estudo de línguas de sinais à luz da LC é a iconicidade cognitiva. Na concepção linguístico-cognitiva, as unidades e as estruturas das línguas são estudadas não como autônomas, mas como manifestações das capacidades cognitivas gerais, da organização conceptual, dos princípios de categorização, dos mecanismos de processamento e da experiência cultural, social e individual (SILVA, 1997). Desse modo, para a LC, a relação forma-significado é regida por um dos princípios fundamentais da organização linguística: a iconicidade. Assume-se, assim, que as formas linguísticas podem refletir aspectos do conteúdo comunicado (HAIMAN, 1985).

Langacker (2008) explica que a iconicidade pode ser identificada, por exemplo, pela forma como as pessoas sequencializam os eventos ocorridos ou conceptualizados, através da comunicação. Por exemplo, ao descrever sua rotina noturna o emissor provavelmente afirmará que chega em casa, toma banho, come, escova os dentes e dorme, mas não dirá que dorme, toma banho, escova os dentes e come, rotina da manhã e não da noite. A tendência de os indivíduos narrarem fatos e ideias, de acordo com a ordem, é chamada pelo autor de iconicidade temporal. Nesse sentido, para a LC, a arbitrariedade e a iconicidade deixam de ser conceitos antagônicos. Logo, podem coexistir, pois ambas refletem processos cognitivos mais amplos inerentes à linguagem.

A partir dessa concepção, surge o conceito de iconicidade cognitiva, cunhado por Wilcox (2004), segundo o qual os polos fonológico (forma) e semântico (significado) de uma estrutura simbólica residem em um mesmo espaço conceptual. Uma vez que o espaço conceptual é suficientemente abrangente para compreender todo o pensamento e o conhecimento, Wilcox (2004) propõe que as semelhanças são distâncias entre estruturas que residem nessa localização multidimensional. Certas noções residem próximas umas das outras no espaço conceptual, porque possuem certas semelhanças. Outras noções residem mais distantes no espaço conceitual, refletindo a sua dissimilaridade. No entanto, todas residem no espaço conceptual.

Assumindo que as noções mencionadas estão organizadas nos polos fonológico e semântico, pode-se compreender que, quanto maior a proximidade entre essas instâncias, maior a similaridade e, em consequência, maior a iconicidade. Ao contrário, quanto maior distância, maior a arbitrariedade. Portanto, a iconicidade cognitiva é definida não como uma relação entre 
a forma de um sinal e algo a que se refere no mundo real, mas como uma relação entre dois espaços conceptuais. A iconicidade cognitiva é uma relação estabelecida através da distância entre os polos fonológicos e semânticos das estruturas simbólicas (WILCOX, 2004).

$\mathrm{Na}$ estrutura linguística da Libras, o polo fonológico é representado pelos cinco parâmetros que formam os itens lexicais: (i) configuração de mãos (CM), forma como as mãos se posicionam na produção do sinal; (ii) ponto de articulação (PA), local onde incide a mão configurada, podendo essa mão tocar alguma parte do corpo ou estar em um espaço neutro (região do corpo em frente ao tronco); (iii) orientação (Or), direção da palma da mão durante a produção do sinal; (iv) movimento (M), parâmetro complexo, porque pode envolver uma vasta rede direcional, desde os movimentos internos da mão, do pulso, os movimentos direcionais no espaço até conjuntos de movimentos no mesmo sinal que podem ser em linhas reta, curva, sinuosa ou circular, em várias direções e posições; (v) expressão facial e corporal ou expressão não manual (ENM), que podem fazer parte ou não de um sinal.

Quadros, Pizzio e Rezende afirmam que "[e]xpressões faciais têm função adjetiva, pois podem ser incorporadas ao substantivo independente da produção de um adjetivo" para apontar tamanho ou grau de intensidade (2008, p. 3). A incorporação das expressões faciais está atrelada ao processo de corporificação. No caso dos itens lexicais relacionados às emoções humanas, as ENMs codificam aspectos importantes da construção de sentido do sinal. Nessa concepção, observamos uma relação metonímica em que ENMs são parte de um todo conceitual expresso pelos sinais adjetivos estudados. A importância dos processos metonímicos nos estudos da Libras também foi ressaltada por Nunes (2014), para quem a corporificação está atrelada às relações com os órgãos do corpo e suas funções estão presentes na produção de sinais, visto que o corpo é parte integrante na composição dos sinais.

Em termos prototípicos, a classe gramatical dos adjetivos especifica conceitos de propriedades, como azul, alto, inteligente (LANGACKER, 2008, p. 95). Os oitenta sinais analisados em Sessa (2018) foram categorizados como itens lexicais que ativam conceitos de EMOÇÃO. Nosso senso comum sobre emoção, um conceito abstrato, envolve a existência de certas causas que levam às emoções, e as emoções que possuímos nos levam a produzir certas respostas, com base no seguinte modelo conceptual em termos esquemáticos: causa da emoção $\rightarrow$ emoção $\rightarrow$ (controle da emoção) $\rightarrow$ resposta.

Essa teoria popular geral das emoções deriva da aplicação da metáfora conceitual de nível genérico CAUSAS SÃO FORÇAS, fundamentada pelo esquema imagético FORÇA. Segundo Kövecses (2020, p. 45), “a metáfora aplica-se à primeira parte e à segunda parte do modelo acima", pois 
[...] tudo que leva a uma emoção é conceituado como uma causa que possui 'força' suficiente para efetuar uma mudança de estado no self (tornar-se emocional), e a própria emoção também é vista como uma causa com 'força' para efetuar algum tipo de resposta (fisiológica, comportamental e/ou expressiva).

Assim, "no modelo cognitivo-cultural prototípico, uma situação é conceituada como uma entidade poderosa que leva à emoção e a própria emoção é conceituada como outra entidade poderosa que produz algum tipo de ação ou conjunto de ações” (KÖVECSES, 2020, p. 45-46), portanto EMOÇÕES SÃO FORÇAS no nível do frame. A metáfora no nível mais esquemático dos esquemas imagéticos CAUSAS SÃO FORÇAS é fundamentada metonimicamente a partir das respostas corporais causadas pela emoção. Logo as metonímias gerais CAUSA DA EMOÇÃO PELA EMOÇÃO e EFEITO DA EMOÇÃO PELA EMOÇÃO sustentam, em termos esquemáticos, conceitos de emoções, que, mesmo descontextualizados, são categorizados figurativamente, a partir de sua base corporal. As relações entre os níveis do frame e do esquema imagético, subjacentes aos conceitos de emoção analisados aqui, são representados na Figura (1).

Figura 1 - Relações conceptuais para EMOÇÃO

Fonte: elaborada pelas autoras (2021).

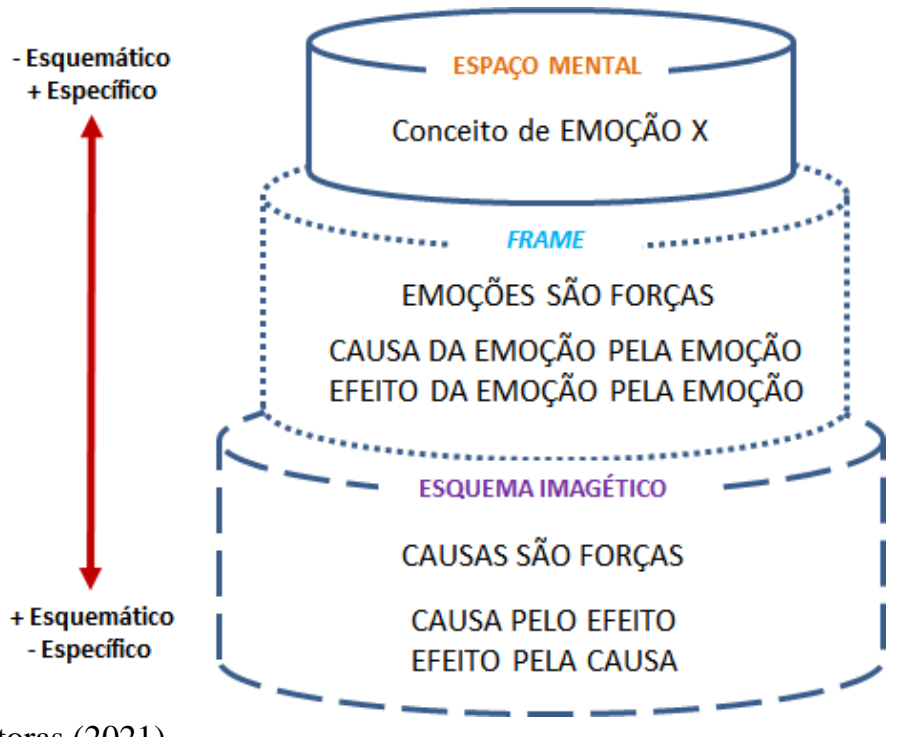

Inspiradas na metáfora de Fauconnier e Turner (2002) de que a linguagem é a ponta do iceberg e na hierarquia proposta por Kövecses (2020), ilustramos, na Figura (1), as relações conceptuais que subjazem aos conceitos de EMOÇÃO. No nível dos espaços mentais, que atua na memória de trabalho, conceitos de emoções específicos são ativados, baseados em frames e esquemas imagéticos. Nessa concepção, a Figura (1) ilustra a assunção de que conceitos de emoção são fundamentados pelas metáforas e metonímias gerais apontadas na Figura (1) como propriedades primitivas das emoções. A essas visões gerais figurativas sobre conceitos de 
emoção, outras metonímias e metáforas ligadas a conceitos específicos seriam somadas, quando ativamos um conceito de emoção.

A configuração cônica da representação deve-se à natureza processual da ativação de frames que estruturam conceptualmente os conceitos de emoção e à relação hierárquica de contiguidade e esquematicidade das estruturas conceptuais. As partes do cone comprimem-se e se expandem, desde os espaços mentais aos esquemas imagéticos, estruturas pré-conceptuais analógicas, que, em conjunto com frames (e domínios-matrizes ${ }^{6}$ ), encontram-se armazenados na memória de longo prazo, disponíveis para ativação em diferentes níveis, nos bastidores da conceptualização.

\section{Aspectos metodológicos}

Na realização da pesquisa de mestrado, ao invés de capturar as imagens do próprio site do Dicionário Digital da Língua Brasileira de Sinais - INES, os sinais foram gravados por Sessa (2018), a fim de manter a qualidade das imagens, reproduzindo-as fielmente, de acordo com a fonte. As fotos dessa gravação são reproduzidas na seção de análise dos sinais selecionados para aumento de clareza ${ }^{7}$.

Além da imagem, foram descritos os parâmetros utilizados no sinal, a fim de facilitar o entendimento de como este é realizado, já que as imagens estáticas nem sempre davam conta de, por si só, mostrar totalmente a produção do sinal. Como o Dicionário Eletrônico do INES é acessado por um link que propicia o acesso inicial geral, não foi possível informar o link de cada verbete em separado. Todavia, repetimos o link junto à descrição dos sinais analisados.

\section{Processos cognitivos em sinais adjetivos da Libras}

Com base na análise dos sinais adjetivos em Libras, postulamos quatro projeções metonímicas, percebidas recorrentemente nos dados analisados: EXPRESSÃO NÃO MANUAL POR EMOÇÃO, INTENSIDADE/DIREÇÃO DE MOVIMENTO POR EMOÇÃO, CONTATO POR EMOÇÃO, CONTENÇÃO POR EMOÇÃO, consideradas especificações da metonímia geral PARTE PELO TODO. Essas metonímias fundamentam conceptualmente a relação entre os polos fonológico (revelado nos cinco parâmetros da Libras) e semântico. Logo, influenciam na gradação da iconicidade

\footnotetext{
${ }^{6}$ Como já apontamos, não trabalharemos com o nível do domínio-matriz, que estaria em outra parte do cone, entre as partes para frame e esquema imagético.

${ }^{7}$ Foram adotadas, na gravação, as diretrizes de acessibilidade em comunicação televisiva regidas pela ABNT (NBR 15290), pois, apesar de não se ter a finalidade de exibição do trabalho, essa norma é de grande valia para a obtenção de qualidade de imagem. Também foram consideradas as normas propostas pelo Grupo de Pesquisa Vídeo-Registro em Libras, que dispõe sobre a apresentação de trabalhos acadêmicos nessa língua quanto ao local de gravação e à visualização do sinalizante (MARQUES; OLIVEIRA, 2012).
} 
cognitiva dos sinais que expressam EMOÇÃO. Em outras palavras, quanto mais projeções metonímicas, maior será a aproximação entre os polos e, em consequência, maior o grau de iconicidade cognitiva.

A projeção metonímica EXPRESSÃO NÃO MANUAL POR EMOÇÃO foi utilizada para categorizar os sinais adjetivos em que o sentido da emoção, intrínseca ao sinal analisado, transparece no parâmetro ENM. O termo intensidade da metonímia INTENSIDADE/DIREÇÃO DE MOVIMENTO POR EMOÇÃO foi empregado para referir o papel de repetições do parâmetro movimento dos articuladores em determinada direção (parâmetro orientação), com ou sem velocidade, conforme a configuração do sinal, e, ainda, para aludir ao modo como esse movimento é produzido, com leveza ou firmeza. Há casos que envolvem intensidade e direção e casos em que apenas um aspecto fundamenta o conceito. A metonímia CONTATO POR EMOÇÃO foi postulada nos sinais em que o parâmetro ponto de articulação atua na conceptualização do adjetivo analisado. Por fim, a projeção metonímica CONTENÇÃO POR EMOÇÃO evidencia a relação entre o parâmetro configuração de mãos $(\mathrm{CM})$ e o conceito do sinal.

As metonímias propostas estão ligadas predominantemente a esquemas imagéticos de ESPAÇO, CONTENÇÃO e UNIDADE/MULTIPLICIDADE. O esquema imagético de ESPAÇO subjaz ao conceito de iconicidade cognitiva, que, por sua vez, relaciona-se ao caráter viso-espacial dos sinais da Libras, produzidos na parte superior do corpo, considerado um CONTÊINER que guarda as propensões humanas. O esquema imagético de UNIDADE/MULTIPLICIDADE relaciona-se às experiências perceptuais de seres, objetos e ambientes compostos de partes que formam um todo.

Em termos conceptuais, os sinais adjetivos estudados podem ser categorizados por meio do seguinte caminho: esquemas imagéticos fundamentam frames/domínios, que fundamentam as metonímias subjacentes aos sinais, que, por sua vez, são processadas a partir da abertura de um espaço mental - uma base para acesso a estruturas conceptuais de longo prazo na ativação de metonímias e metáforas. Essas metonímias funcionam como base para processos metafóricos.

Na Figura (2), ilustramos a concepção dos sinais adjetivos para emoção estudados como unidade simbólica. Os retângulos pontilhados representam o caráter facultativo da subjacência de outras metáforas e metonímias específicas ao conceito de emoção, além daquelas basilares já apontadas na Figura (1). Os retângulos com linhas cheias ilustram elementos basilares dos polos fonológico e semântico da EMOÇão. 
Figura 2 - Sinais adjetivos para emoção como unidade simbólica

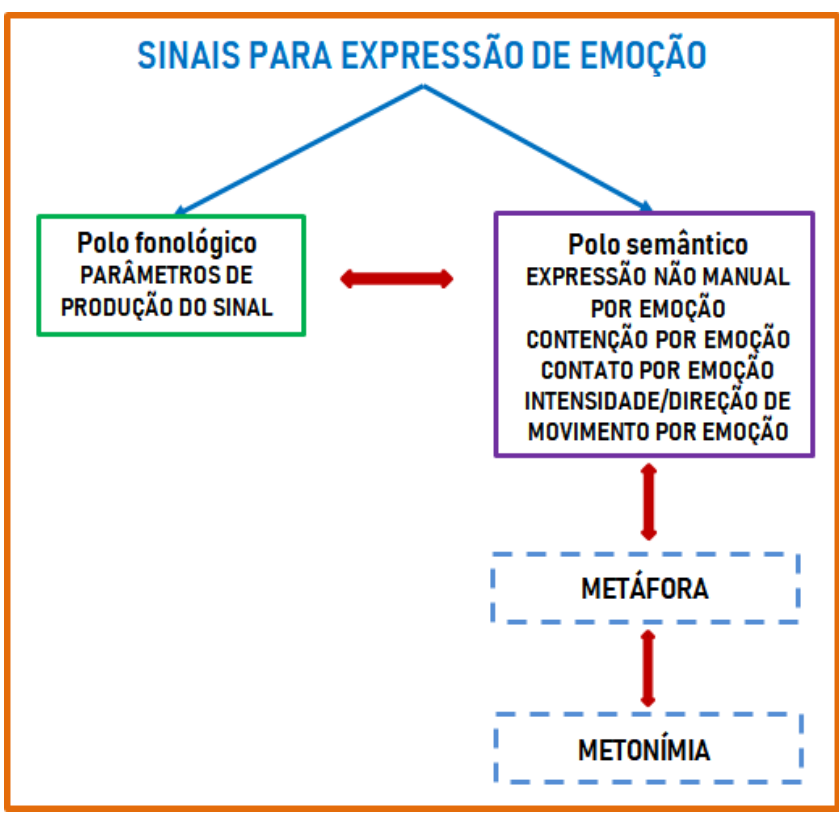

Fonte: elaborada pelas autoras (2021).

As próximas subseções iniciam com a imagem da produção do sinal, seguida da descrição deste. Em termos textuais, os títulos das subseções expressam o conceito de emoção expresso pelo sinal.

\section{ABORRECIDO}

Figura 3 - Sinalização de ABORRECIDO

Fonte: Sessa (2018, p. 49)

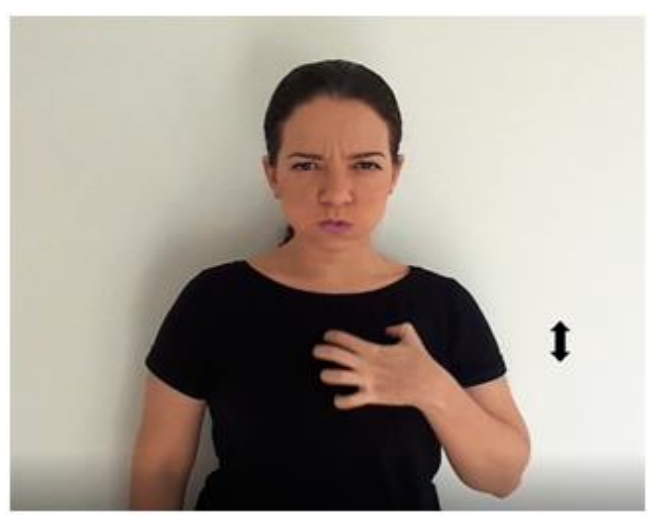

Descrição: mão sinalizante aberta, com os dedos separados e semiflexionados. As pontas dos dedos encostam-se no peito, com a palma da mão voltada para dentro e movimentam-se para cima e para baixo com agilidade (http://www.ines.gov.br/dicionario-de-libras/main_site/libras.htm).

No sinal ABORRECIDO, o polo fonológico aproxima-se do polo semântico através dos cinco parâmetros. A CM é frequentemente usada como um gesto significando algo feroz, em razão de os dedos semiflexionados simularem garras (de um felino ou um monstro). Essa CM 
também simula uma demarcação da localização onde o sentimento é guardado. O MO, por ser ágil, demonstra incômodo e inquietude. As ENMs apontam com clareza o sentimento de irritação. A OR (palma para dentro) e o PA demonstram que a emoção está dentro do peito, fator que destaca a presença de corporificação nesse sinal, pois é produzido na parte do corpo à qual se costuma atribuir a produção de sentimentos, devido à resposta física a emoções que causam aceleração de batimentos cardíacos ou sensação de falta/represamento de ar.

A testa franzida e as bochechas cheias, aliadas à posição dos dedos da mão, semiflexionados em arco, como se estivesse segurando algo, e ao movimento da mão, pode ser relacionado à forma como a raiva é experienciada em várias culturas, em que a mente/cabeça metonimicamente representa a parte do corpo que sofre alteração por conta do sentimento da raiva, que causa irritação e perda de racionalidade/equilíbrio emocional - daí a mente/cabeça como um CONTÊINER que enche até explodir. Essa forma convencional de conceituar a raiva evidencia a ativação da metáfora RAIVA É SUBSTÂNCIA EM UM CONTÊINER, em termos esquemáticos, no nível dos esquemas imagéticos, especificada, no nível do frame, como RAIVA É FLUIDO QUENTE/GÁS/AR EM UM CONTÊINER.

Podemos postular a metáfora conceptual mais específica, em nível de espaço mental, ABORRECER-SE É BUFAR, visto que na conceptualização em Libras para aborrecimento, raiva, não se trata de um líquido ou gás, mas um ar acumulado que infla as bochechas, transmitindo a ideia de que o sentimento se movimentando dentro da pessoa está a ponto de explodir, como uma panela de pressão que precisa soltar esse ar. Dessa forma, o caminho conceptual para a construção de sentido de ABORRECIDO recruta estruturas conceptuais mais esquemáticas a mais específicas.

Devido à correlação entre a vivência da emoção e as respostas físicas causadas por tais emoções, postulamos um estágio metonímico para as metáforas subjacentes ao sentido expresso pelo sinal ABORRECIDO. Assim, as metonímias EFEITO PELA CAUSA e EFEITO DA EMOÇÃO PELA EMOÇÃO, fundamentam, respectivamente, as referidas metáforas RAIVA É SUBSTÂNCIA EM UM CONTÊINER e RAIVA É FLUIDO QUENTE/GÁS/AR EM UM CONTÊINER / ABORRECER-SE É BUFAR ${ }^{8}$. Os esquemas imagéticos de FORÇA e EQUILÍBRIO fundamentam tais metáforas, visto que EMOÇÕES SÃO FORÇAS.

Esse sentido é fundamentado pelos esquemas imagéticos de CONTÊINER (CHEIO/VAZIO), uma especificação do esquema CONTENÇÃO, e de MOVIMENTO, devido ao deslocamento da mão. Tais esquemas fundamentam as metonímias EXPRESSÃO NÃO MANUAL POR EMOÇÃO, CONTATO

\footnotetext{
${ }^{8}$ Sobre metonímias gerais e específicas, citamos o estudo de Ibáñez e Usón (2007).
} 
POR EMOÇÃO, INTENSIDADE/DIREÇÃO DE MOVIMENTO POR EMOÇÃO e CONTENÇÃO POR EMOÇÃO, ligadas ao polo semântico do conceito expresso pelo sinal ABORRECIDO.

Postulamos que o esquema imagético EQUILÍBRIO (perdido) subjaz predominantemente à conceptualização de emoções que levam a respostas corporais de algo a ser expelido. Isso se deve a um necessário extravasamento de sentimentos ruins aprisionados, considerando a forma como os parâmetros de sinalização representam respostas corporificadas ao vivenciar de tais emoções. Por outro lado, aos sentimentos positivos ou íntimos subjazem o esquema imagético CONTÊINER, como se fizessem parte dos seres humanos de forma mais inerente.

\section{CONTENTE}

Figura 4 - Sinalização de CONTENTE

Fonte: Sessa (2018, p. 74)

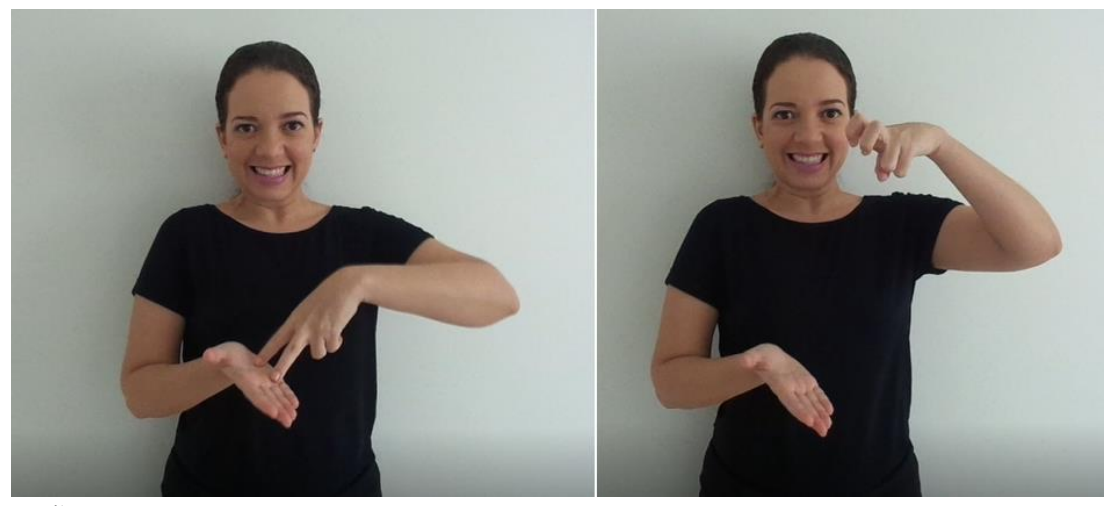

Descrição: mão em "V", repousando pelas pontas dos dedos sobre a palma da outra mão que está aberta, com dedos unidos e palma para cima. A mão que está em "V" movimenta-se para cima, enquanto os dedos indicador e médio flexionam-se repetidas vezes (http://www.ines.gov.br/dicionario-delibras/main_site/libras.htm).

A CM de CONTENTE também é usada como classificador de pessoa, em que os dedos representam as pernas, evidenciando o significado do sinal. O MO revela a metáfora ALEGRIA/CONTENTAMENTO É PARA CIMA, no nível do frame ALEGRIA/CONTENTAMENTO, pois retrata que a pessoa está saltando de alegria. Na ENM, identifica-se a metonímia EXPRESSÃO NÃO MANUAL POR EMOÇÃO e também a metáfora ALEGRAR-SE/CONTENTAR-SE É SORRIR, no nível espaço mental, por se tratar de uma especificação da metáfora subjacente ao parâmetro MO. Podemos afirmar que se identifica a corporificação nesse sinal, nos três parâmetros acima descritos, porque representam a experiência cinestésica do momento em que uma pessoa pula por estar contente.

As metáforas subjacentes ao sinal CONTENTE - ALEGRIA/CONTENTAMENTO É PARA CIMA e ALEGRAR-SE/CONTENTAR-SE É SORRIR -, também são fundamentadas pela metonímia mais 
esquemática EFEITO PELA CAUSA, que passa por níveis de especificação gerando as metonímias MOVIMENTO ASCENDENTE PELA EMOÇÃO e MOVIMENTO ASCENDENTE DO CORPO PELA EMOÇÃO, devido às respostas comportamentais como efeito da emoção experienciada. A relação estabelecida entre a resposta corporal ao EFEITO DA EMOÇÃO e o domínio do MOVIMENTO, leva às conceptualizações metafóricas postuladas para o sinal CONTENTE.

Postulamos, portanto, a subjacência dos esquemas imagéticos de ESPAÇO (VERTICALIDADE) e MOVIMENTO (ORIGEM-PERCURSO-DESTINO), devido ao movimento ascendente de uma das mãos em relação à outra que permanece como origem do movimento. Logo, as metonímias CONTATO POR EMOÇÃO e INTENSIDADE/DIREÇÃO DE MOVIMENTO POR EMOÇÃO também foram descritas como basilares para tal conceito.

\section{FOGOSO}

Figura 5 - Sinalização de FOGOSO

Fonte (Sessa, 2018, p. 92)

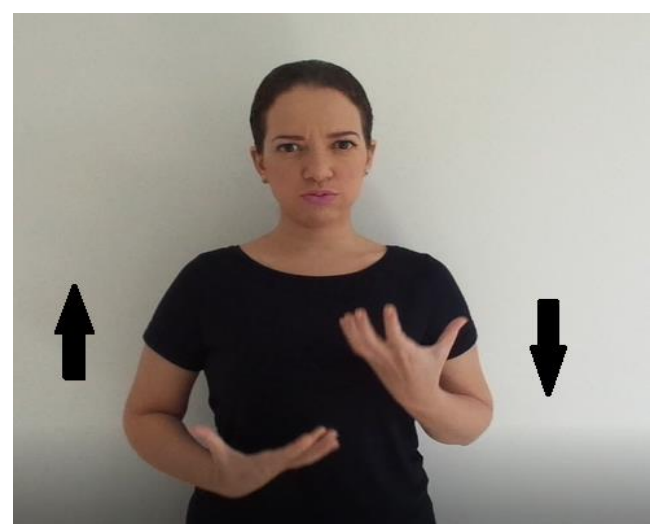

Descrição: mãos abertas, dedos separados e semiflexionados com palma para cima, movimentando-se para cima e para baixo alternadamente. Concomitantemente, os dedos também se movimentam, distendendo-se e flexionando-se (http://www.ines.gov.br/dicionario-de-libras/main site/libras.htm).

No sinal FOGOSO, observa-se a metonímia conceptual MÃO POR OBJETO, pois a CM juntamente com a OR (palma para cima) e o MO (para cima e para baixo alternadamente) lembram a representação de chamas de fogo na metonímia INTENSIDADE/DIREÇÃO DE MOVIMENTO POR EMOÇÃO. Cabe salientar que esse sinal também é utilizado para o substantivo fogo, porém, ao ser usado como adjetivo, não se refere à coisa, mas está ligado à metáfora EMOÇÃO É CALOR, uma especificação, em nível de frame, da metáfora mais esquemática EMOÇÃO É TEMPERATURA.

O caminho conceptual dessas metáforas está baseado nas metonímias EFEITO PELA CAUSA, mais esquemática/geral, e EFEITO DA EMOÇÃO PELA EMOÇÃO, mais específica. O 
aumento/intensidade da temperatura é um dos efeitos provocados pelas emoções, daí a metonímia INTENSIDADE DA TEMPERATURA DO CORPO PELA INTENSIDADE DA EMOÇÃO. COMO a conceptualização de FOGOSO envolve o frame de INTENSIDADE, observamos a subjacência dos esquemas imagéticos FORÇA e QUANTIDADE.

Além desses esquemas imagéticos, podemos perceber na CM a subjacência do esquema imagético CONTENÇÃo, pois sua forma sugere que as mãos estão cheias de algo. A presença desse esquema serve de base para a postulação da metonímia CONTENÇÃO POR EMOÇÃO. A ENM evidencia a metonímia EXPRESSÃO NÃO MANUAL POR EMOÇÃO, pois as bochechas enchem-se levemente e, em seguida, esvaziam-se como se as chamas estivessem sendo assopradas.

\section{OTIMISTA}

Figura 6 - Sinalização de OTIMISTA
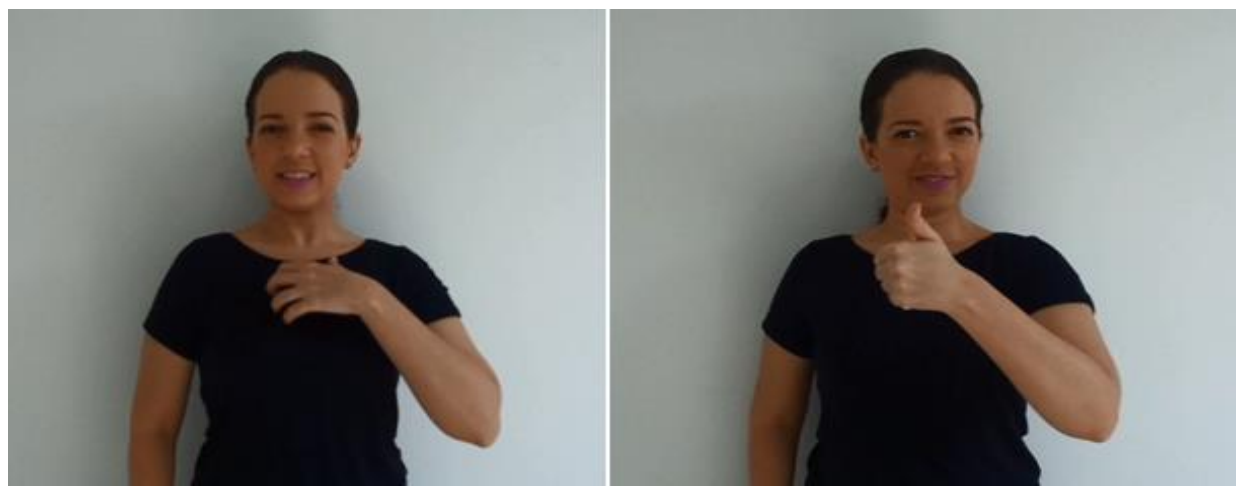

Fonte: Sessa (2018, p. 118)

Descrição: mão aberta com os dedos separados e semiflexionados. As pontas dos dedos encostam-se ao peito, com a palma da mão voltada para dentro. Em seguida, mão fechada com polegar distendido e palma para dentro na frente do tronco (http://www.ines.gov.br/dicionario-delibras/main_site/libras.htm).

O conceito OTIMISTA é composto pelos sinais SENTIMENTO e BOM. No primeiro, identifica-se o esquema imagético de CONTÊINER (CHEIO/VAZIO), porque a CM, a OR e o PA demonstram que os sentimentos seriam produzidos e localizados metaforicamente no coração, como se o peito fosse um recipiente. Assim, propõem-se as metonímias CONTENÇÃo POR EMOÇÃO e CONTATO POR EMOÇÃO na construção de sentido basilar do sinal.

Em BOM, assim como nos sinais LEGAL e MAGNÍFICO, observamos a CM amplamente utilizada como gesto significando positividade, revelando a metáfora conceptual LEGAL/MAGNÍFICO/ÓTIMO É PARA CIMA. A ENM produzida durante esse sinal reforça essa ideia através da metáfora ALEGRAR-SE/CONTENTAR-SE É SORRIR, fundamentada, portanto, pela metonímia EXPRESSÃO NÃO MANUAL POR EMOÇÃO. 
O caminho da conceptualização de OTIMISTA, em termos da relação metonímiametáfora, é semelhante ao postulado para CONTENTE: a metonímia mais esquemática EFEITO PELA CAUSA é especificada em POSIÇÃO ASCENDENTE PELA EMOÇÃO e POSIÇÃO ASCENDENTE DE PARTE DO CORPO PELA EMOÇÃO, devido às respostas comportamentais aos efeitos causados por emoções, representados no sinal por meio da posição da mão com o polegar apontando para cima. Assim, as metáforas LEGAL/MAGNÍFICO/ÓTIMO É PARA CIMA, mais esquemática, e ALEGRAR-SE/CONTENTAR-SE/SER POSITIVO É SORRIR, mais específica, subjazem ao sentido de OTIMISTA.

DOIDO

Figura 7 - Sinalização de DOIDO

Fonte: Sessa (2018, p. 84)

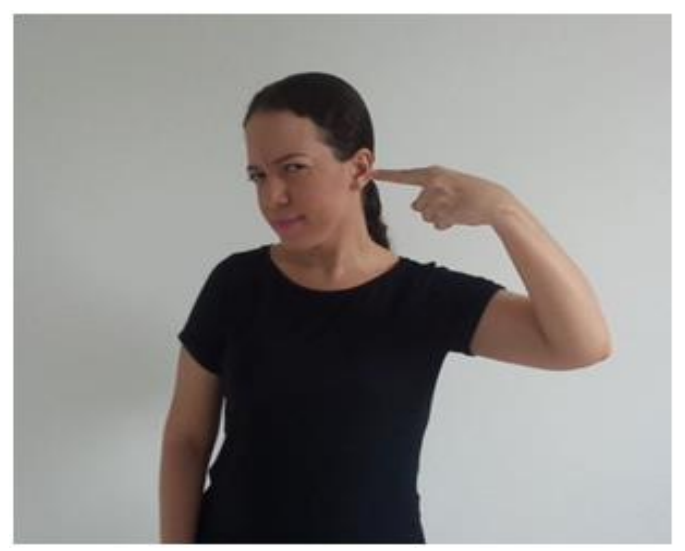

Descrição: mão fechada com dedo indicador distendido girando em torno do ouvido (http://www.ines.gov.br/dicionario-de-libras/main_site/libras.htm).

Na ENM do sinal DOIDO, notamos a metonímia EXPRESSÃO NÃO MANUAL POR EMOÇÃO, pois revela a estranheza que alguém pode ter ao presenciar uma atitude insana através da testa franzida e dos lábios cerrados. Esse sinal é frequentemente utilizado como gesto para designar loucura, talvez porque se atribua às pessoas que sofrem de perturbação mental a característica, dentre outras, de ouvir vozes, ou de falar algo que não vale a pena ouvir. Nesse sentido, percebemos, no sinal DOIDO, uma relação com gesto usado cotidianamente junto ao emprego da palavra doido na modalidade oral da Língua Portuguesa, ou sozinho para expressar o conceito de doido.

Além disso, comumente, loucos são retratados em desenhos e representações como pessoas com ouvidos tapado com as mãos, fato que pode ter relação com a localização (PA) do sinal. O MO remete à expressão metafórica "parafuso solto", muito utilizada em referência a 
indivíduos que não se comportam de acordo com os padrões estabelecidos socialmente, revelando a metáfora conceptual PESSOAS SÃO MÁQUINAS, que podem dar defeito. A metonímia INTENSIDADE/DIREÇÃO DE MOVIMENTO POR EMOÇÃO também fundamenta esse conceito adjetival.

PESSOAS SÃO MÁQUINAS, classificada por estudiosos como metáfora de semelhança, em princípio, não envolveria um estágio metonímico, a não ser que consideremos o recrutamento da estrutura parcial de um frame/domínio-fonte para conceituar uma parte do alvo, resultante de metonímia. Nesse caso, a experiência com manipulação de máquinas compostas de parafusos, em que verificamos um defeito, quando não se consegue aperto de parafusos necessários ao funcionamento desta, seria associada por analogia a uma pessoa que se comporta de forma inesperada.

Assim, parte da máquina (parafuso) seria tomada para conceituar uma parte da pessoa (comportamento inesperado), gerando a metonímia COMPORTAMENTO DA PESSOA PELA PESSOA. Essa relação seria generalizada (esquematizada) para conceptualização de PESSOAS como MÁQUINAS. Tal concepção pode ainda ser fundamentada pelo fato de que, embora metáforas envolvam material conceptual da memória de longo prazo, a ativação desse conteúdo particionado é processado na memória de trabalho por meio de espaços mentais, que operam e otimizam o processamento linguístico-conceptual.

Por meio da análise dos sinais ABORRECIDO, CONTENTE, FOGOSO, OTIMISTA e DOIDO procuramos demonstrar como as metonímias e as metáforas desempenham importante papel na conceptualização dos sinais para exprimir emoção em Libras. Esses processos metonímicos e metafóricos são fundamentados frames/domínios, que, por sua vez, são fundamentados por esquemas imagéticos. Como evidência do caráter corporificado da Libras, diferentes graus de iconicidade cognitiva foram postulados, a partir do papel das metonímias na conceptualização dos conceitos adjetivos para emoção, considerados como unidades simbólicas, constituídas de um polo fonológico, composto pela representação dos parâmetros de produção do sinal, e de um polo semântico, relacionado às metonímias basilares ligadas à representação dos parâmetros de produção dos sinais.

Além dessas metonímias, metáforas também fundamentam a conceptualização dos sinais adjetivos pesquisados. Tais projeções metafóricas estão ligadas a conceitos culturalmente convencionais partilhados a respostas corporais resultantes da interação social e física com o ambiente.

Na Figura (3), ilustramos a escala de prototipicidade com base na iconicidade cognitiva postulada para os conceitos analisados aqui. Abaixo do sinal, encontra-se o sinal matemático 
"+" seguido do número de ocorrências de sinais que apresentam a subjacência das mesmas metonímias em relação aos oitenta adjetivos para EMOÇão analisados em Sessa (2018).

Figura 8 - Categorização radial dos sinais adjetivos para EMOÇÃO

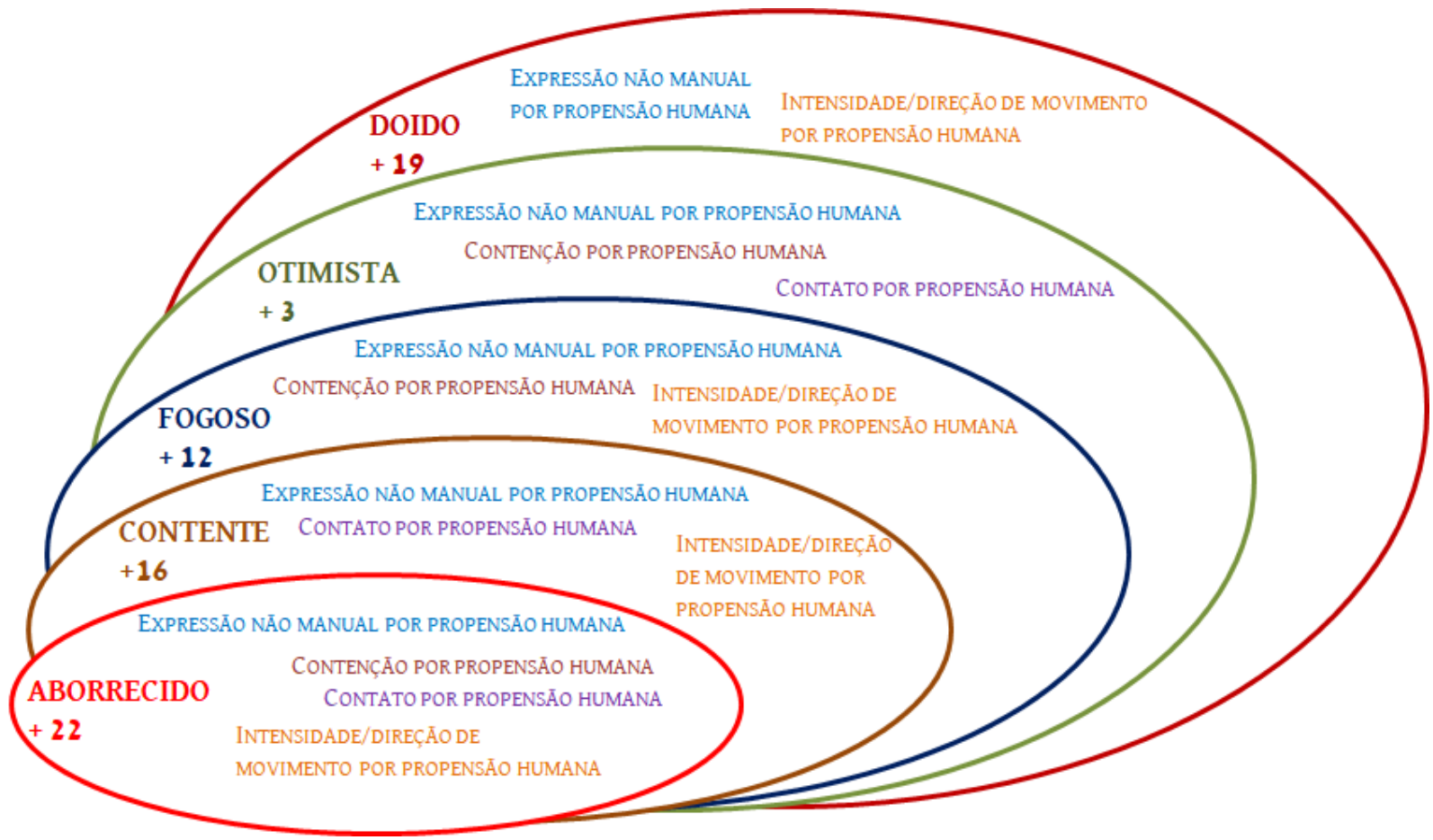

Fonte: elaborada pelas autoras (2021).

Com base na recorrência, a ENM e o PA foram considerados mais eficazes na diminuição da distância entre polos fonológico e semântico dos sinais para EMOÇÃO: a primeira figurou nos oitenta sinais e o segundo, em quarenta e seis sinais adjetivos, dos quais nenhum deles ficou no último nível de radialidade. Além do critério numérico, destacamos a relevância metonímia CONTATO POR EMOÇÃO, ligada ao PA, na construção de sentido dos dados pesquisados, devido ao caráter corporificado dos sinais, na medida em que parte do corpo é usada como espaço conceptual de sinalização.

\section{Considerações finais}

Esperamos que, por meio deste trabalho, tenha sido possível evidenciar a pertinência dos conceitos da Linguística Cognitiva aplicados aos estudos da Libras. Embora o objeto desta análise sejam conceitos relacionados à emoção, consideramos que seja possível aplicar semelhante análise a outros adjetivos e categorias gramaticais da Libras.

A pesquisa continua em andamento, investigando a conceptualização de sinais com função adjetiva em contexto de uso da Libras, por meio de vídeos postados na Internet. Além disso, as reflexões continuam a ser tecidas com vistas a refinar o papel das estruturas 
conceptuais hierarquicamente organizadas, nos moldes da Teoria da Metáfora Conceptual Estendida de Kövecses (2020), em sua relação com a Teoria da Integração Conceptual, buscando o aprofundamento da relação metáfora-metonímia no tange ao seu papel na conceptualização de conceitos da Libras.

\section{Referências}

ASSOCIAÇÃO BRASILEIRA DE NORMAS TÉCNICAS. NBR 15290: Acessibilidade em comunicação na televisão. Rio de Janeiro: ABNT, 2005.

DICIONÁRIO DA LÍNGUA BRASILEIRA DE SINAIS - LIBRAS - ACESSIBILIDADE BRASIL. Disponível em: http://www.ines.gov.br/dicionario-de-libras/main_site/libras.htm. Acesso em: 15 jul. 2017.

EVANS, V.; GREEN, M. The nature of cognitive linguistics: assumptions and commitments. In: EVANS, V.; GREEN, M. (autores). Cognitive Linguistics: An Introduction. Edinburgh: Edinburgh University Press, 2006. p. 27-53.

FAUCONNIER, G. Mappings in thought and language. Cambridge: Cambridge University Press, 1997.

FAUCONNIER, G.; TURNER, M. The way we think: conceptual blending and the mind's hidden complexities. New York: Basis Books, 2002.

FERRARI, L. Introdução à Linguística Cognitiva. São Paulo: Contexto, 2011.

FILLMORE, C. J. Frame semantics. In: GEERAERTS, D. (ed.). Cognitive linguistics: basic readings. Berlin; New York: Mouton de Gruyter, 2006, p. 373-400.

GEERAERTS, D. (ed.). Cognitive linguistics: basic readings. Berlin/New York: Mouton de Gruyter, 2006.

GIBBS Jr., R. W.; COLSTON, H. L. The cognitive psychological reality of image schemas and their transformations. In: GEERAERTS, Dirk (ed.). Cognitive linguistic: basic readings. Berlin/New York: Mouton de Gruyter, 2006. p. 239-268.

HAIMAN, J. Natural syntax: iconicity and erosion. Cambridge: Cambridge University Press, 1985.

HAMPE, B. Image schemas in cognitive linguistics: introduction. In: HAMPE, B.; GRADY, J. E. (eds.). From perception to meaning: image schemas in cognitive linguistics. Berlin; New York: Mouton de Gruyter, 2005. p. 1-14.

HEINE, B.; CLAUDI, U.; HÜNNEMEYER, F. Grammaticalization: a conceptual framework. Chicago: The University of Chicago Press, 1991.

IBÃNEZ, F. J. R. M.; USÓN, R. M. High-level metaphor and metonymy in meaning construction. In: RADDEN, G.; KÖPCKE, K.-M.; BERG, T.; SIEMUND, P. (ed.). Aspects 
of Meaning Construction in Lexicon and Grammar. Amsterdam; Philadelphia: Jonh Benjamins, 2007. p. 33-49.

JOHNSON, M. The body in the mind. Chicago: The University of Chicago Press, 1987.

KÖVECSES, Z. Language, mind and culture: a practical introduction. New York: Oxford University Press, 2006.

KÖVECSES, Z. Metaphor: a practical introduction. New York: Oxford University Press, 2010.

KÖVECSES, Z. Emotion concepts in a new light. Rivista Italiana di Filosofia del Linguaggio, Calábria, Special Issues SFL, p. 42-54, 2020.

KÖVECSES, Z. Extended conceptual metaphor theory. Cambridge; New York: Cambridge University Press, 2020.

LAKOFF, G. Women, fire and dangerous things. Chicago: Chicago University Press, 1987.

LAKOFF, G.; JOHNSON, M. Metáforas da vida cotidiana [coordenação de tradução Mara Sophia Zanotto]. Campinas: Mercado de Letras; São Paulo: EDUC, 2002.

LANGACKER, R. W. Foundations of Cognitive Grammar. Stanford: Stanford University Press, 1987.

LANGACKER, R. W. Cognitive grammar: a basic introduction. New York: Oxford University Press, 2008.

MARQUES, R. R.; OLIVEIRA, J. S. A normatização de artigos acadêmicos em Libras e sua relevância como instrumento de constituição de corpus de referência para tradutores. In: CONGRESSO NACIONAL DE PESQUISAS EM TRADUÇÃO E INTERPRETAÇÃO DE LIBRAS E LÍNGUA PORTUGUESA, 3, 2012, Florianópolis. Anais [...]. Florianópolis: UFSC, 2012. Disponível em: http://www.congressotils.com.br/anais/anais/tils2012_metodologias_traducao_marquesoliveir a.pdf. Acesso em: 05 dez. 2017.

NUNES, V. F. Narrativas em Libras: análise de processos cognitivos. 2014. $153 \mathrm{f}$. Dissertação (Mestrado em Linguística) - Programa de Pós-Graduação em Letras, Universidade Estadual do Rio de Janeiro, Rio de Janeiro, 2014.

QUADROS, R. M.; PIZZIO, A. L.; REZENDE; P. L. F. Língua Brasileira de Sinais II. Florianópolis: UFSC, 2008. Disponível em:

https://www.libras.ufsc.br/colecaoLetrasLibras/eixoFormacaoEspecifica/linguaBrasileiraDeSi naisII/assets/482/Lingua_de_Sinais_II_para_publicacao.pdf. Acesso em: $11 \mathrm{dez} .2021$.

ROSCH, Eleanor. Principles of categorization. In: ROSCH, E.; LLOYD, B. B. (eds.). Cognition and Categorization. Hillsdale, NJ: Lawrence Erlbaum, 1978. p. 27-48.

SESSA, G. A. B. S. Expressão por emoção: uma abordagem cognitiva de adjetivos em Língua Brasileira de Sinais. 2018. 140 f. Dissertação (Mestrado em Linguística) - Programa 
de Pós-Graduação em Letras, Universidade do Estado do Rio de Janeiro, Rio de Janeiro, 2018.

SILVA, A. S. A Linguística Cognitiva: uma breve introdução a um novo paradigma em linguística. Revista Portuguesa de Humanidades, Braga, v. 1, n. 1-2, p. 59-101, 1997.

WILCOX, S. Cognitive iconicity: conceptual spaces, meaning, and gesture in signed languages. Cognitive Linguistics, Berlin, v. 15, n. 2, p. 119-147, 2004.

\section{Sobre as autoras}

Glênia Aguiar Belarmino da Silva Sessa (Orcid iD: https://orcid.org/0000-0003-4999-8812)

Doutoranda no Programa de Pós-Graduação em Letras da Universidade do Estado do Rio de Janeiro (UERJ); mestra em Letras pela mesma instituição e licenciada em Pedagogia pelo Instituto Nacional de Educação de Surdos (INES). É professora de Libras do SENACRJ.

Sandra Pereira Bernardo (Orcid iD: https://orcid.org/0000-0001-6952-9138)

Doutora e mestra em Linguística pela Universidade Federal do Rio de Janeiro (UFRJ); graduada em Letras-Português-Literaturas pela mesma instituição. É professora associada do Departamento de Estudos da Linguagem e docente do Programa de Pós-Graduação em Letras da Universidade do Estado do Rio de Janeiro (UERJ).

Recebido em julho de 2021.

Aprovado em dezembro de 2021. 